\title{
Analysis of growth curves of indigenous male Venda and Naked Neck chickens
}

\author{
D. Norris ${ }^{1 \#}$, J.W. Ngambi ${ }^{1}$, K. Benyi ${ }^{2}$, M.L. Makgahlela ${ }^{1}$, H.A. Shimelis ${ }^{1}$ \\ and E.A. Nesamvuni ${ }^{3}$ \\ ${ }^{1}$ Department of Animal Science, University of Limpopo, Private Bag X 1106, Sovenga 0727, South Africa \\ ${ }^{2}$ Department of Animal Science, University of Venda Private Bag X 5050, Thohoyandou 0950, South Africa \\ ${ }^{3}$ Department of Agriculture, Private Bag X 9487, Polokwane 0700, South Africa
}

\begin{abstract}
The objective of this work was to estimate and compare the growth curve parameters for live weight of indigenous Venda and Naked Neck chickens and carry out some analyses to test the existence of differences in the growth pattern between these breeds. The data were collected from the two breeds of chickens that were reared from day-old to 21 weeks of age. Two hundred chickens (100 of each breed) were used. Three different non-linear models, namely Gompertz, Logistic and Richards, were used to define the growth curves of the chickens. Models were compared using Coefficients of determination ( $\mathrm{R}^{2}$ values), A parameter values, the Durbin-Watson Statistic (DW) test for autocorrelation, computing difficulty based on the number of iterations needed for convergence and size of residual variances. The $\mathrm{R}^{2}$ were high for all models: 0.996 , 0.990 and 0.997 for Gompertz, Logistic and Richards, respectively. Residual variances were 2240, 5924 and 1154 for Gompertz, Logistic and Richards, respectively. The Gompertz model was observed to be suitable for explaining the growth of the chickens. Breed differences were observed in the growth parameters of chickens. The Venda breed was observed to be late maturing and heavier at maturity while the Naked Neck was shown to have a higher growth rate, reaching maturity earlier but attaining a lighter mature weight.
\end{abstract}

Keywords: Growth parameters, growth models, breed differences

\# Corresponding author. Email: norrisd@ul.ac.za

\section{Introduction}

Poultry production in most rural parts of South Africa is characterized by small scavenging operations. Most of the poultry in these operations are indigenous chickens that are considered to be of low productivity. However, extensive research has not been done to determine the production potential of these indigenous chickens. Their growth and other production parameters have not been adequately studied. Furthermore, very little in terms of genetic improvement has been done to improve their productivity.

Modelling of growth curves is useful because it provides means for visualizing growth patterns over time, and the generated equations can be used to predict the expected weight of a group of animals at a specific age (Tzeng \& Becker, 1981; Yakupoglu \& Atil, 2001; Sengul \& Kiraz, 2005). It has been found that it is possible to select on the shape of the growth curve (Merrit, 1974; Mignon-Grasteau et al., 2001). In a number of studies, growth trend parameters have been found to be highly heritable and have been successfully used in selection studies (Merrit, 1974; Mignon-Grasteau et al., 2001; Sengul \& Kiraz, 2005). Growth curves have been modelled for turkeys (Anthony et al., 1991; Sengul \& Kiraz, 2005), ostriches (Du Preez et al., 1992; Cilliers et al., 1995; Sabbioni et al., 1999), quails (Anthony et al., 1991) and chickens (Anthony et al., 1991; Mignon-Grasteau et al., 2000; Mignon-Grasteau et al., 2001).

A number of growth models exist that can be used to determine the age-live weight relationship of animals. These growth curves have different characteristics and different mathematical limitations. It becomes important therefore to carefully consider the choice of an appropriate model that best describes a particular growth pattern.

The aim of this study was to estimate growth curves and their parameters using different growth models to determine the age-live weight relationships and to further examine whether there are breed differences in the growth parameters of two indigenous chickens breeds. 


\section{Material and Methods}

The data were collected from two breeds of chickens, the indigenous Venda and Naked Neck breeds. A total of 200 male chickens (100 of each breed) were used. The birds were reared from day-old to 21 weeks of age. The study was conducted at the experimental farm of the University of Limpopo between February and August 2005. Mean temperatures in winter (April to July) range between 10.1 and $28.4{ }^{\circ} \mathrm{C}$ and in summer (August to March) between 18 and $36^{\circ} \mathrm{C}$.

The chickens were reared together on a litter floor in an open house. They were medicated similarly and were subjected to the same managerial, hygienic and climatic conditions. Standard commercial starter and grower diets were provided ad libitum and the birds had free access to water. Chickens were wingbanded at 1 day of age and body weights were recorded at the end of each one-week period.

Widely used non-linear growth models, Gompertz, Logistic and Richards were fitted to estimate the mean age-live weight relationship. The mathematical relations of these models are as follows:

\section{Gompertz : $\mathrm{W}=\mathrm{A}^{*} \operatorname{Exp}(-\operatorname{Exp}(\mathrm{b}-\mathrm{ct}))$ \\ Logistic $\quad: \quad W=A /\left(1+b^{*} \operatorname{Exp}(-c t)\right)$ \\ Richards $\quad: \quad W=A\left(1-b^{*} \operatorname{Exp}(-k t)\right)^{\wedge} M$}

where $\mathbf{W}$ is the corresponding weight at time $\mathbf{t}$. $\mathbf{A}$ is the adult value or asymptote, $\mathbf{b}, \mathbf{c}, \mathbf{k}, \mathbf{M}$ are model parameters.

Parameters were estimated by the non-linear regression procedure and the Levenberg-Marquardt method of SPSS (2005). Models were compared using Coefficients of determination ( $\mathrm{R}^{2}$ values), A parameter values, the Durbin-Watson Statistic (DW) test for autocorrelation and the computing difficulty based on the number of iterations needed for convergence. The A parameter which is the asymptotic limit of the weight when age $(\mathrm{t})$ approaches infinity does not imply that $\mathbf{A}$ is the heaviest weight attained by the individual, but it indicates the average weight of the mature animal, independent of short-term fluctuations in weight due to temporary environmental effects (Lopez de Torre et al., 1992; Berry et al., 2005). This parameter was tested for lack of bias in the choice of an appropriate growth model. The Durbin-Watson Statistic tests the null hypothesis that the residuals from an ordinary least-squares regression are not autocorrelated against the alternative that the residuals follow an AR1 process. The Durbin-Watson Statistic ranges in value from 0 to 4 . A value near 2 indicates non-autocorrelation, a value toward 0 indicates positive autocorrelation and a value toward 4 indicates negative autocorrelation (SPSS, 2004). When autocorrelation is present, serious errors can be made in statistical inferences about the regression model due to misinterpretation of statistics (Yakupoglu \& Atil, 2001). Residual variances were also inspected for goodness of fit.

Based upon the decision of the choice of the most appropriate model, differences between the growth parameters of the breeds were tested using the t test procedures. The A model parameters (and standard errors) and Coefficients of determination $\left(\mathrm{R}^{2}\right)$ estimated from different models are presented in Table 1.

Table 1 Coefficients of determination $\left(\mathrm{R}^{2}\right)$ and Parameter $\mathbf{A}$ values of non-linear models

\begin{tabular}{ccccc}
\hline Model & Breed & $\mathrm{R}^{2}$ & A & s.e. \\
\hline \multirow{2}{*}{ Gompertz } & Venda & 0.996 & 2832.5 & 121.7 \\
& Naked Neck & 0.996 & 2700.0 & 75.79 \\
Logistic & & & \\
& Venda & 0.989 & 2414.7 & 99.26 \\
& Naked Neck & 0.990 & 2419.0 & 72.46 \\
Richards & Venda & 0.997 & 4056.1 & 685.0 \\
& Naked Neck & 0.997 & 3026.2 & 197.9 \\
\hline
\end{tabular}

s.e. - standard error 
The $\mathrm{R}^{2}$ values were high for all growth models indicating a significant relationship between age and weight in both breeds. Sengul \& Kiraz (2005) found high Coefficients of determination for Gompertz, Logistic, Morgan-Mercer-Flodin and Richards in a study of growth curves in turkeys. Yakupoglu \& Atil (2001) also found high $\mathrm{R}^{2}$ values in a study of growth in broilers using Gompertz and Bertalanffy growth models. Based on $\mathrm{R}^{2}$ alone, all models seemed to be appropriate to describe the association between age and live weight.

Residual variance may vary according to increasing and decreasing asymptotic body weight and thus small A parameter values would be desirable for the decision of best-fit model (Yakupoglu \& Atil, 2001). Lopez de Torre et al. (1992), in a study of the effect of growth curves on cow efficiency, compared the A parameter to the average weight from 60 to 97 months of age to assess the best fit from the different growth models. Based on the degree of difference between the 60 - 97 months average weight and the A parameter, a decision on the appropriateness of the model was made. In the present study, the largest value of the $\mathbf{A}$ parameter was observed under the Richards model and may indicate possible overestimation of mature weight by this model. The standard errors for the A parameter values estimated under the Richards model were also large.

Although the data set was not large and thus may not have posed computing difficulties under all models, there were fewer iterations needed for convergence under the Gompertz model compared to other models. The assessment of residual variances is presented in Table 2.

Table 2 Residual variances of non-linear models relating growth by age for two chicken genotypes

\begin{tabular}{lcc}
\hline Model & Venda & Naked Neck \\
\hline Gompertz & 2240.13 & 2231.61 \\
Logistic & 5924.38 & 6288.49 \\
Richards & 1154.64 & 1556.30 \\
\hline
\end{tabular}

The residual variances were larger for the Logistic growth model than the Gompertz and Richards models. The Richards model had the smallest residual variances. This was observed for both breeds. Yakupoglu \& Atil (2001) found lower residual variances for the Gompertz model compared to the Bertalanffy. In a study by Sengul \& Kiraz (2005) the lowest residual variances were found under the MMF model followed by Gompertz, Logistic and Richards models, respectively. On the basis of residual variances in the present study, the Richards and Gompertz models seem to be the most appropriate models for explaining of the growth of indigenous chickens.

Autocorrelation values derived from the Durbin-Watson procedure are presented in Table 3.

Table 3 Durbin-Watson Autocorrelation values for non-linear models relating growth by age for two chicken genotypes

\begin{tabular}{lcc}
\hline Model & Venda & Naked Neck \\
\hline Gompertz & 0.65 & 0.63 \\
Logistic & 0.47 & 0.43 \\
& & 0.50 \\
\hline
\end{tabular}

Autocorrelation values for all models were close to zero, indicating positive autocorrelation which may pose problems with statistical inferences about the models. 
The overall assessment of the growth models seems to indicate that the Gompertz model better describes the data for both breeds. The Richards model may also be used to describe the data though its major shortcoming stems from the biased estimate of the A parameter with its large standard error. The Logistic model does not seem appropriate for description of the growth data in this study.

Based on this assessment, the Gompertz model was further used to carry out comparisons of the growth parameters for the two breeds. The Gompertz growth curves are shown in Figure 1. As seen in the curves, fitted lines are very close to the observed values. Since consecutive or repeated measurements are usually autocorrelated, the growth model was fitted to individual birds to remove possible bias in the statistical inference on the growth parameters. The average of the parameters from individual curves was then compared between breeds. According to Jayaraman \& Zeide (2005), in the presence of autocorrelation, unbiased parameter values may still be obtained but there could be underestimation of their variance.

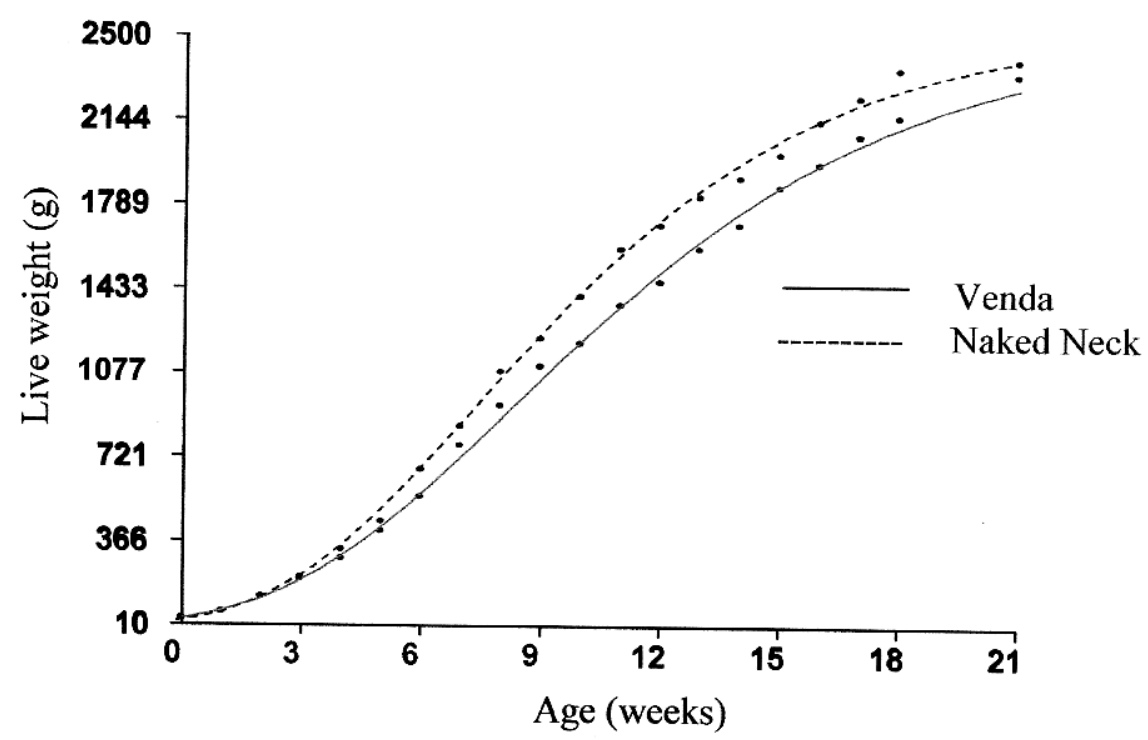

Figure 1 Growth curves of Venda and Naked Neck chickens

The Gompertz equation parameters are shown in Table 4.

Table 4 Growth curves parameters of chickens as affected by breed

\begin{tabular}{lccc}
\hline & Mature weight (g) & Rate of Growth & $\begin{array}{c}\text { Age at maximum weight } \\
\text { gain (wks) }\end{array}$ \\
\hline Breed & $2691^{\mathrm{a}}(88)$ & $0.169^{\mathrm{a}}(0.0084)$ & $8.23^{\mathrm{a}}(0.21)$ \\
Naked Neck & $2819^{\mathrm{b}}(129)$ & $0.138^{\mathrm{b}}(0.0084)$ & $9.60^{\mathrm{b}}(0.37)$ \\
Venda & &
\end{tabular}

${ }^{\mathrm{ab}}$ column means with different superscripts differ at $\mathrm{P}<0.05$; s.e. in parentheses

There were differences in all growth parameters indicating differences in growth of the two breeds. The Naked Neck had a higher growth rate, reached maturity earlier but had a lighter mature weight. On the other hand, the Venda breed was late maturing but heavier at maturity. Some study (unpublished) carried out at the Animal Improvement Institute of the Agricultural Research Council (ARC) showed the Venda breed 
attaining sexual maturity at 143 days of age, reaching a weight of $2.01 \mathrm{~kg}$ at 20 weeks, while the Naked Neck breed reached a weight of $1.95 \mathrm{~kg}$ at 20 weeks and attained sexual maturity at 155 days.

The phenotypic variances of growth parameters are shown in Table 5.

Table 5 Phenotypic variances of growth parameters for two chicken genotypes

\begin{tabular}{lccc}
\hline & Mature weight (g) & Rate of Growth & $\begin{array}{c}\text { Age at maximum weight } \\
\text { gain (wks) }\end{array}$ \\
\hline Breed & & & \\
Naked Neck & 7817 & 0.000707 & 0.04 \\
Venda & 19816 & 0.000712 & 0.13 \\
\hline
\end{tabular}

The phenotypic variances were larger for mature weight and age at maximum gain in the Venda breed than in the Naked Neck while the variances for rate of growth were similar in the two breeds. This indicates that there is larger variation in mature weight and age at maximum weight gain in the Venda than in the Naked Neck chickens. Given the fact that the two breeds were raised under similar conditions, it can be assumed that there is a higher genetic variation for mature weight and age at maximum weight gain in the Venda than in the Naked Neck chicken. This suggests that there is a larger scope for rapid genetic improvement of mature weight through selection in the Venda breed than in the Naked Neck.

Correlations between growth curve parameters in this study were high and showed a similar pattern in both breeds (Tables 6). The relationship between the asymptotic mature weight and rate of growth has biological importance (Lopez de Torre et al., 1992). The high negative correlation (-0.94 and -0.90) observed between mature weight and growth rate indicates that chickens that grow faster do not attain a large mature weight compared to those that mature more slowly in early life. This is also confirmed by the results shown in Table 4. The Venda breed for instance has a slower growth than the Naked Neck but reaches a larger mature weight. This negative correlation may pose a challenge if the objective in an improvement program is to increase the rate of growth as this would result in lower mature weights. The negative correlation between rate of growth and age at maximum weight gain indicates that faster growing chickens attain maximum weight at an earlier age than those that grow slower.

Table 6 Phenotypic correlations between growth parameters for two chicken genotypes

\begin{tabular}{lccc}
\hline & Mature weight (g) & Rate of Growth & $\begin{array}{c}\text { Age at maximum weight } \\
\text { gain (wks) }\end{array}$ \\
\hline Mature weight (g) & & $\mathbf{- 0 . 9 0}$ & $\mathbf{0 . 9 0}$ \\
Rate of Growth & -0.93 & & $\mathbf{- 0 . 7 7}$ \\
$\begin{array}{l}\text { Age at maximum } \\
\text { weight gain (wks) }\end{array}$ & 0.96 & -0.88 & \\
\hline
\end{tabular}

Above diagonal - Naked Neck; Below diagonal - Venda

\section{Conclusions}

The Gompertz growth curve is appropriate for describing the age-live weight relationship in the Venda and Naked Neck indigenous breeds. The results showed evidence that there are breed differences in the growth of the Venda and Naked Neck chickens. The development of growth curves for the two indigenous chicken breeds provides information about the average mature weights and growth rates of these breeds. Further studies should be carried out to estimate the heritability of the growth curve parameters. This 
should make it possible to make selection decisions based on the shape of the growth curves thus offering opportunity for development of a selection procedure that could be used in the genetic improvement of the productivity of these breeds.

\section{Acknowledgements}

Financial assistance of the National Research Foundation (Gun 2070145) and SANPAD is gratefully acknowledged. Statistical advice given by C.Z. Roux is greatly appreciated.

\section{References}

Anthony, N.B., Emmerson, D.A., Nestor, K.E. \& Bacon, W.L., 1991. Comparison of growth curves of weight of selected populations of turkeys, quail and chickens. Poult. Sci. 70, 13-19.

Berry, D.P., Horan, B. \& Dillon, P., 2005. Comparison of growth curves of three strains of female dairy cattle. Anim. Sci. 80, 151-160.

Brown, D. \& Rothery, P., 1993. Models in Biology. Mathematics, Statistics and Computing. John Wiley \& Sons, New York.

Cilliers, S.C., Du Preez, J.J., Maritz, J.S. \& Hayes, J.P., 1995. Growth curves of ostriches (Struthio camelus) from Oudthoorn in South Africa. Anim. Sci. 61, 161-164.

Du Preez, J.J., Jarvis, M.J.F., Capatos, D. \& De Kock, J., 1992. A note on the growth curves for the ostrich (Struthio camelus). Anim. Prod. 54, 150-152.

Jayaraman, K. \& Zeide, B., 2005. The effect of autocorrelation on growth estimates. J. Sustainable Forestry. 20 (4), 37-49.

Lopez de Torre, G., Candotti., J.J., Reverter, A., Bellido, M.M., Vasco, P., Garcia, L.J. \& Brinks, J.S., 1992. Effects of growth curve parameters on cow efficiency. J. Anim. Sci. 70, 2668-2672.

Merrit, E.S., 1974. Selection for growth rate of broilers with a minimum increase in adult size. Proc. $1^{\text {st }}$ World Congress of Genetics Applied to Livestock. Madrid, Spain. 951-958.

Mignon-Grasteau, S., Piles, M., Varona, L., de Rochambeau, H., Poivey, J.P., Blasco, A. \& Beaumont C., 2000. Genetic analysis of growth curve parameters for male and female chickens resulting from selection on shape of growth curve. J. Anim. Sci. 78, 2515-2524.

Sabbioni, A., Superchi, P., Bonomi, A., Summer, A. \& Boidi, G., 1999. Growth curves of intensively reared ostriches (Struthio camelus) in Northern Italy. Proc. 50 ${ }^{\text {th }}$ EAAP Congress. July, 2000.

Sengul, T. \& Kiraz, S., 2005. Non-linear models of growth curves in large white turkeys. J. Vet. Anim. Sci. 29, 331-337.

SPSS, 2005. SPSS for Windows. Release 13.0. SPSS Inc.

Tzeng, R. \& Becker, W.A., 1981. Growth parameters of body and abdominal fat weights in male broiler chickens. Poult. Sci. 60, 1101-1105.

Yakupoglu, C. \& Atil, H., 2001. Comparison of growth curve models on Broilers. II. Comparison of models. Online J. Biol. Sci. 1 (7), 682-684. 